\title{
Suitability mapping for renewable energy potential in the North Sea - results from the BLAST project
}

\author{
Els VERFAILLIE, Belgium \\ Ghent University (UGent) - Department of Geography \\ Krijgslaan 281 - S8 B-9000 Gent \\ Current address: \\ Ghent Port Company ampc \\ John Kennedylaan 32 - Haven 3000 A, B-9042 Gent \\ e-mail: els.verfaillie@havengent.be
}

\author{
Alain DE WULF, Belgium \\ Ghent University (UGent) - Department of Geography \\ Krijgslaan 281 - S8 B-9000 Gent \\ Michel GOETHALS, Belgium \\ Ghent University (UGent) - Department of Geography \\ Krijgslaan 281 - S8 B-9000 Gent
}

Stefaan GYSENS, Belgium

Flemish Government, Agency for Maritime and Coastal Services, Coastal Division

Vrijhavenstraat 3, B-8400 Oostende

Ellen MEIRE, Belgium

Ghent University (UGent) - Department of Geography

Krijgslaan 281 - S8 B-9000 Gent

Philippe DE MAEYER, Belgium

Ghent University (UGent) - Department of Geography

Krijgslaan 281 - S8 B-9000 Gent

Topic F: careful marine planning

\section{INTRODUCTION}

The Interreg IV B BLAST project (www.blast-project.eu) has a primary focus on "Bringing land and sea together", by harmonizing and integrating data between land and sea. Work package 6 of the BLAST project aims to develop new common policies and a web based decision support system (DSS) supporting Integrated Coastal Zone Management (ICZM) under the emerging climate change. One of the indicators of climate change of the DSS is renewable wave energy potential. In the search for optimal spaces to produce renewable energy (RE) important aspects are available power, investment costs and the spatial impact. Due to the high demand for land and sea use by different actors, especially in the coastal zone, a long-term dynamic spatial planning strategy becomes more and more important and could result in space reservation for future activities (e.g. adaptation and mitigation measures).

This paper describes the methodology to obtain suitability maps for wave energy parks in the BLAST North Sea area. The suitability maps are made by a GIS based multi-criteria decision analysis approach. Two different time-scales (1960-1989 and 2070-2099) and corresponding climate change projections of wave energy are used for the suitability maps presented in this paper. More results from this study in the framework of the BLAST project are given in the BLAST report (Verfaillie et al., 2012).

For this study, wave energy projections have been used. The projections are based on the medium emission (A1B) scenario (Nakicenovic et al., 2000) of the Intergovernmental Panel on Climate Change (IPCC). The medium emission scenario describes a world that has rapid economic growth, quick spreading of new and efficient technologies, and a global population that reaches 9 billion mid-century and then gradually declines. It also relies on a balance between different energy sources (Lowe et al., 2009). 
To select a suitable location for wave energy within the North Sea, different location based criteria have to be compared and weighted against each other. Such a location based multi-criteria analysis is called a GIS based multi-criteria decision analysis approach (GIS-MCDA) (Malczewski, 2006). Recent GIS-MCDA studies for wave energy suitability analysis have been done by Prest et al. (2007), Ydens and Meirschaert (2008), Nobre et al. (2009) and Beels (2009). To find a suitable location for wave energy, a balance between minimal cost and maximal production has to be found by balancing wave power resource potential, economical considerations, technological specifications, environmental and social conflicts (Beels, 2009).

The criteria for a GIS-MCDA consist of constraints and weighted factors (Figure 1). Restrictions on the study area are called 'constraints' (e.g. shipping channels) and in the restricted areas no exploitation of wave energy is allowed. The result of all constraints in a study area is an extractable wave energy potential map. 'Factors' are parameters with a variable level of suitability (e.g. distance to the harbour - the closer to the harbour, the more suitable for wave energy; wave energy power - the more power, the more suitable). The factors are evaluated for their impact on the installation of a wave energy farm (score $\mathrm{c}_{\mathrm{i}}$ ) and are weighted according to their relevance (weight $\mathrm{W}_{\mathrm{i}}$ ) (Figure 1). As a result, each grid cell from the study area receives a number that indicates its suitability. The result of the factors applied on the study area is a physical wave energy potential map.

The final suitability map of this study will be a combination of the physical wave energy potential map with the extractable wave energy potential map. A third step in this process could be an economical step, to define an economical extractable potential, but this is beyond the scope of this research.

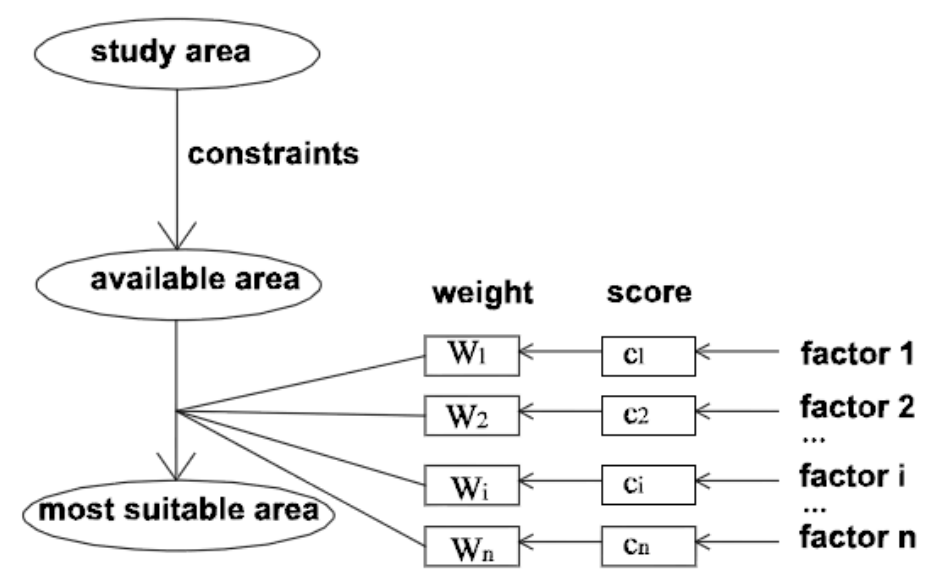

Figure 1: To find a suitable location for wave energy, a GIS-MCDA is performed on the BLAST study area. The suitability depends on constraints (restrictions) and weighted factors (source: Beels (2009))

The study area for this study corresponds with the North Sea area with the exception of France. Limited data are available from the United Kingdom because no active partner participated to Work Package 6 from the BLAST project. Still, some countries provided -incomplete- constraint datasets from the United Kingdom. Factor datasets were available from all countries.

\section{Constraints}

Constraints are restrictions on the study area that do not allow exploitation of wave energy, because activities take place there that are legally allocated (e.g. aggregate extraction, shipping,...). As such, no space is available for wave energy convertors. By combining constraints, some locations are still free for wave energy extraction. For this study, the starting point constraints are taken from report D3.1 from the WINDSPEED project (van der Wal et al., 2011) and from the studies of Beels (2009) and Ydens and Meirschaert (2008). For this study, the following constraints were taken into account:

- Wind mill parks or wind mill park concession zones

- Shipping routes

- Oil and gas installations

- Military zones 
- Pipelines

- Cables

- Nature zones

- Aggregate extraction zones

In Figure 2, the result from the combined constraints in the North Sea area are shown.

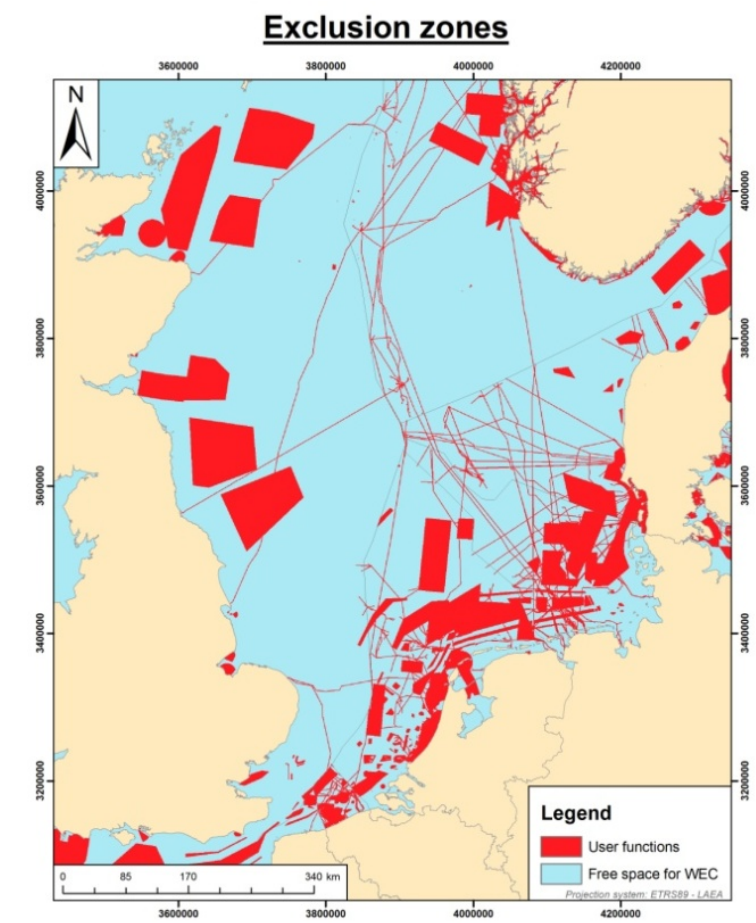

Figure 2: Extractable wave energy potential map after exclusion of all the constraints of sea activities.

Factors

Next to the constraints, weighted factors are taken into account as well. Factors for this study are:

- wave energy

- 2 unperturbed projections (Ortega and Monbaliu, 2012)

- From 1960 to 1989 (baseline or past period), and

- from 2070 to 2099 (far future projection).

- bathymetry

- distance to the harbours

- distance to the coastline

- substrate type

- benthic value

For this study, the suitability analysis does not take into account specific device dependent or economical information, in contrast to the study of Ydens and Meirschaert (2008) and Beels (2009). The weights that are assigned to the different factors are the following:

\begin{tabular}{|l|l|}
\hline Weight [\%] & \\
\hline wave energy power & 53 \\
\hline bathymetry & 5 \\
\hline distance to harbours & 10 \\
\hline distance to coastline & 20 \\
\hline substrate type & 9 \\
\hline benthic value & 3 \\
\hline
\end{tabular}

The weights have been assigned based on the study of Beels (2009) and expert judgement. Each factor map has been classified into relevant classes and each class has received a score $c_{i}$. The 
highest scores are given to the most suitable classes of the factors (e.g. high wave energy power, close to the harbours) and the lowest scores are given to the least suitable classes of the factors.

The combination of the weighted factor maps of the BLAST areas are called physical energy potential maps. These maps are shown in Figures $3 a, 3 b, 4 a$ and $4 b$. Figures $3 a$ and $4 a$ show the physical energy potential maps from respectively the baseline situation and the far future projection. In Figures $3 b$ and $4 b$, the constraints are also shown on the maps. The difference between the baseline maps (Figures $3 \mathrm{a}$ and $3 \mathrm{~b}$ ) and the far future projection maps based on change calculations as explained in Ortega and Monbaliu (2012) (Figures 4a and 4b) indicate that a possible suitability shift can be expected as a result from climate change. There is an expected suitability shift from North to South and from the more remote areas in the Northern part of the North Sea to the more coastal areas in the South-Western part of the North Sea. At the same time, most of the sea activities take place within these coastal zones.

The maps are indicator maps, meaning that they can not be interpreted as 'truth', because the uncertainty within the wave projection datasets depends on different criteria (e.g. choice of climate scenario, boundary conditions of wave models). They give an indication about possible suitable locations for wave energy potential within the North Sea. The main aim of the suitability maps is to show spatial planners and decision makers that the current situation of spatial allocation in the North Sea should be considered in a flexible way. Spatial planners and decision makers should take into account that climate change can have effects on the most suitable locations for wave energy and other forms of RE. Maybe they should consider that certain 'fixed' sea activities (the 'constraints') could be combined with other sea activities. Win-win situations could be created by combining different sea activities (e.g. wave energy and wind energy in 1 common renewable energy park where all the gained energy can be transported to the mainland by 1 single energy transmission system). Wave energy convertor systems are at the moment still in a prototype phase, but it is expected that the ecological impact from this type of energy gain is low (e.g. benthos, fish, seabirds, sediment).

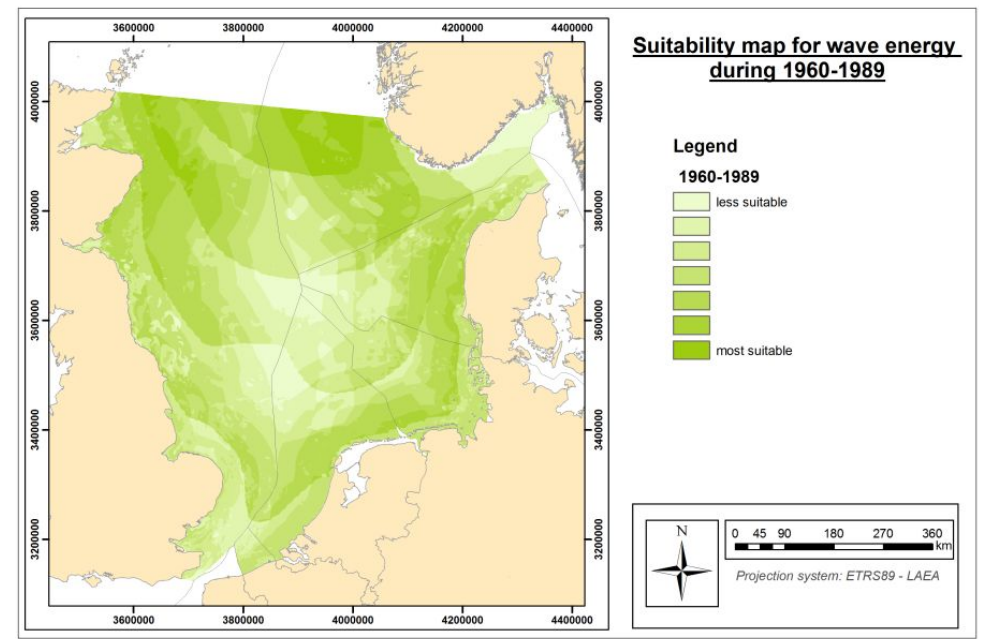

Figure 3a: Suitability map for wave energy parks (baseline situation)

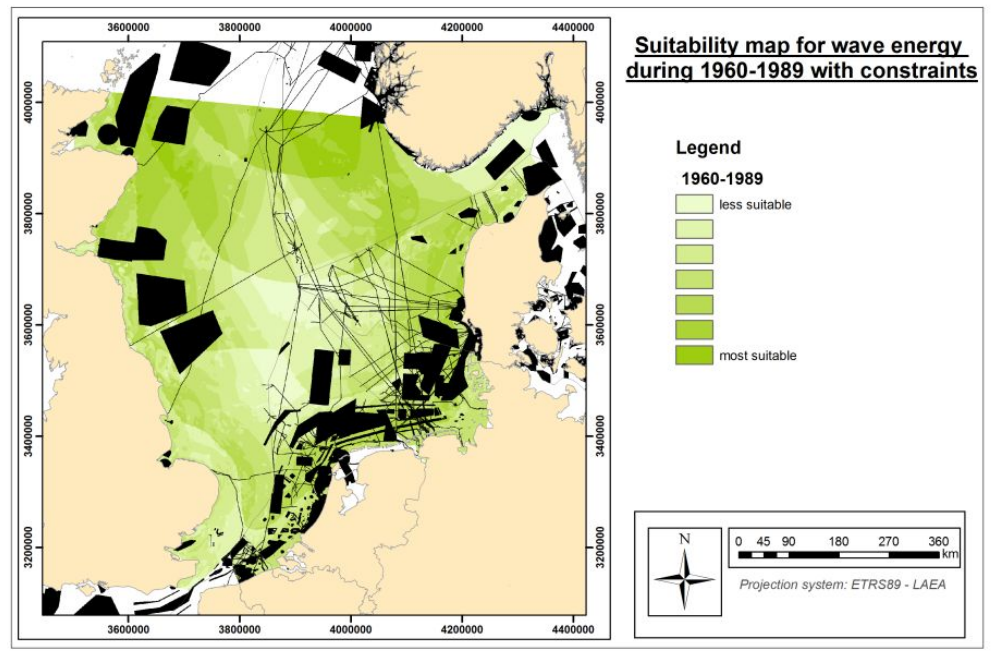


Figure 3b: Suitability map with constraints for wave energy parks (baseline situation)

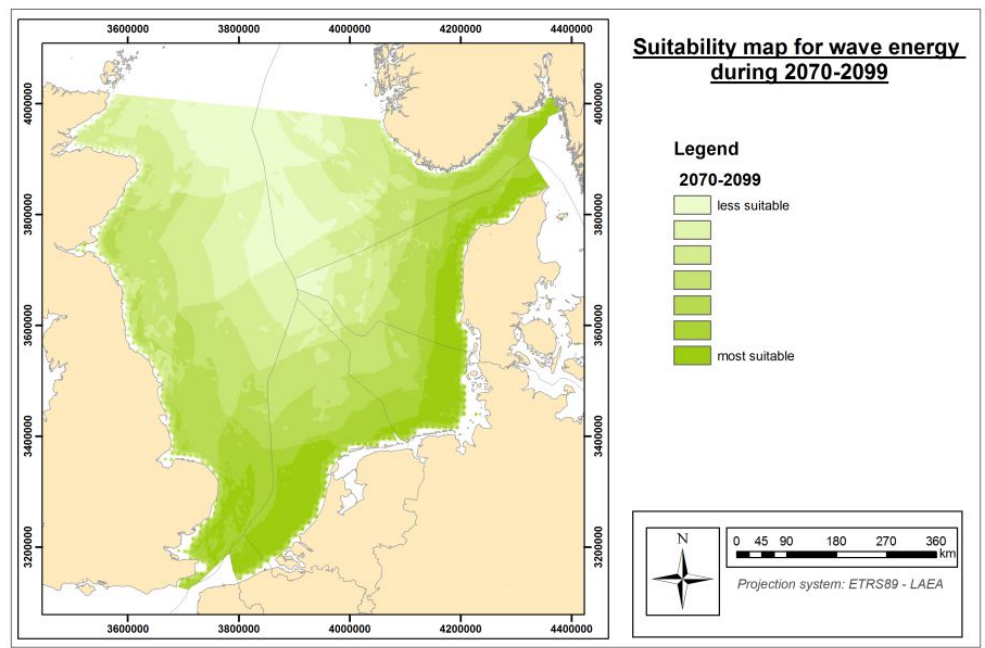

Figure 4a: Suitability map for wave energy parks (far future projection based on calculations of wave energy change (Ortega and Monbaliu (2012)).

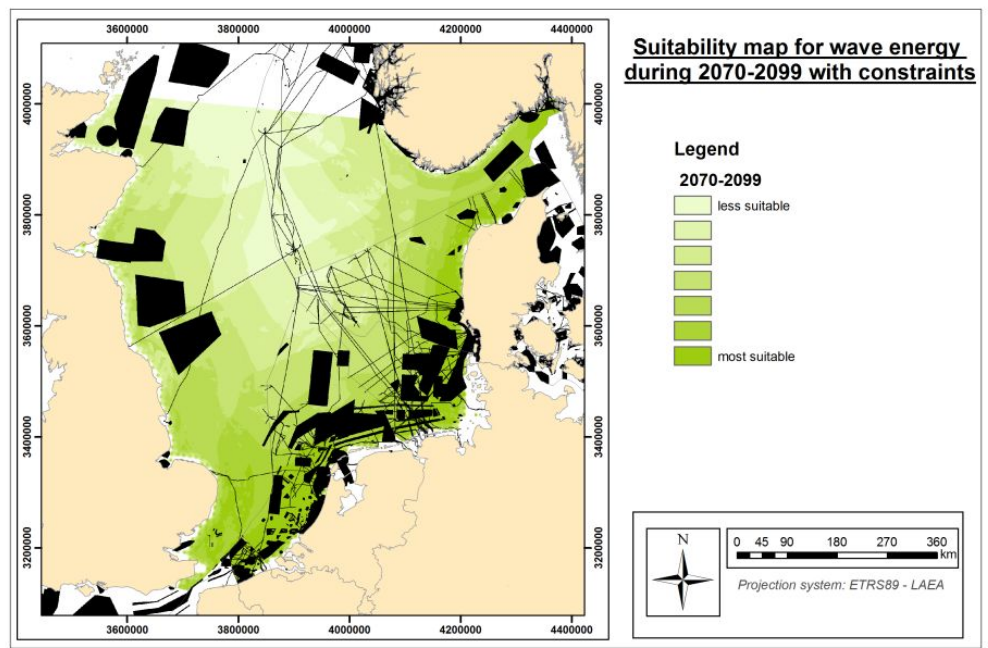

Figure 4b: Suitability map with constraints for wave energy parks (far future projection based on calculations of wave energy change (Ortega and Monbaliu (2012)) 


\section{REFERENCES}

Beels, C., 2009. Optimization of the Lay-Out of a Farm of Wave Energy Converters in the North Sea Analysis of Wave Power Resources, Wake Effects, Production and Cost, Unpublished PhD thesis Ghent University, Ghent.

Lowe, J.A., Howard, T.P., Pardaens, A., Tinker, J., Holt, J., Wakelin, S., Milne, G., Leake, J., Wolf, J., Horsburgh, K., Reeder, T., Jenkins, G., Ridley, J., Dye, S. and Bradley, S., 2009. UK Climate Projections science report: Marine and coastal projections. Exeter: Met Office Hadley Centre.

Malczewski, J., 2006. GIS-based multicriteria decision analysis: a survey of the literature. International Journal of Geographical Information Science, 20(7): 703-726.

Nakicenovic, N., Swart, R. and (Eds.), 2000. Special Report on Emissions Scenarios. A Special Report of Working Group III of the Intergovernmental Panel on Climate Change. Cambridge University Press, Cambridge, UK and New York, NY, USA, 599 pp.

Nobre, A., Pacheco, M., Jorge, R., Lopes, M.F.P. and Gato, L.M.C., 2009. Geo-spatial multi-criteria analysis for wave energy conversion system deployment. Renewable Energy, 34(1): 97-111.

Ortega, H. and Monbaliu, J., 2012. Effect of climate change on North Sea wave energy potential based on UKCP09 Climate Projections - BLAST deliverable from WP6 (www.blast-project.eu).

Prest, R., Daniell, T. and Ostendorf, B., 2007. Using GIS to evaluate the impact of exclusion zones on the connection cost of wave energy to the electricity grid. Energy Policy, 35(9): 4516-4528.

van der Wal, J.T., Quirijns, F.J., Leopold, M.F., Slijkerman, D.M.E., Glorius, S.G. and Jongbloed, R.H., 2011. Inventory of current and future presence of non-wind sea use functions - Second edition, WINDSPEED WP3 Report D3.1.

Verfaillie, E., De Maeyer, P., De Wulf, A., Goethals, M., Gysens, S. and Meire, E., 2012. The renewable energy indicator: wave energy potential - BLAST deliverable from WP 6 (www.blastproject.eu).

Ydens, I. and Meirschaert, V., 2008. Onderzoek naar een economische exploitatie van het golfenergiepotentieel in de Noordzee m.b.v. ArcGIS, Unpublished MSc dissertation, Ghent University. 